\title{
MASJID DALAM KAJIAN SOSIAL POLITIK,BUDAYA DAN PEMBANGUNAN KESEJAHTERAAN
}

\section{Oleh}

Shohibul Anshor Siregar

FORUM KAJIAN TETAP KEMASJIDAN institut bakti nasrallah Medan 15 Januari 2018 
- Mengikat persaudaraan antar komunitas muslim

- Mengikat perjanjian dengan non-muslim

- Membangun sistem politik (syura)

- Meletakkan slstem dasar ekonomi

- Membangun keteladanan pada elit masyarakat

- Menjadikan ajaran Islam sebagai sistem nilai dalam masyarakat

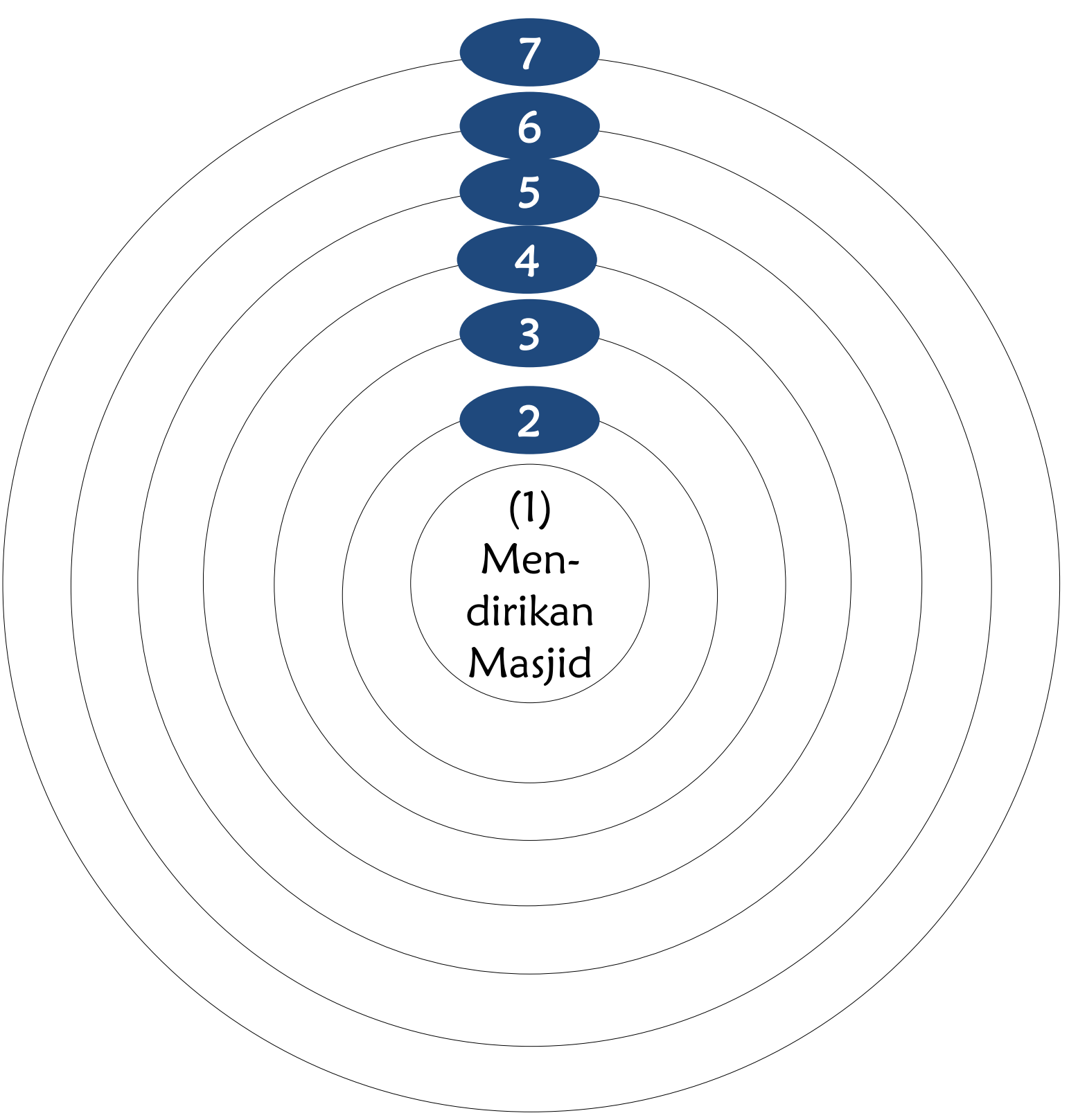


(FRED W RIGGS)

(1) Masjid sebagai institusi Islam akan beroleh pengaruh dari semua faktor perubahan sosial, dan begitu sebaliknya.

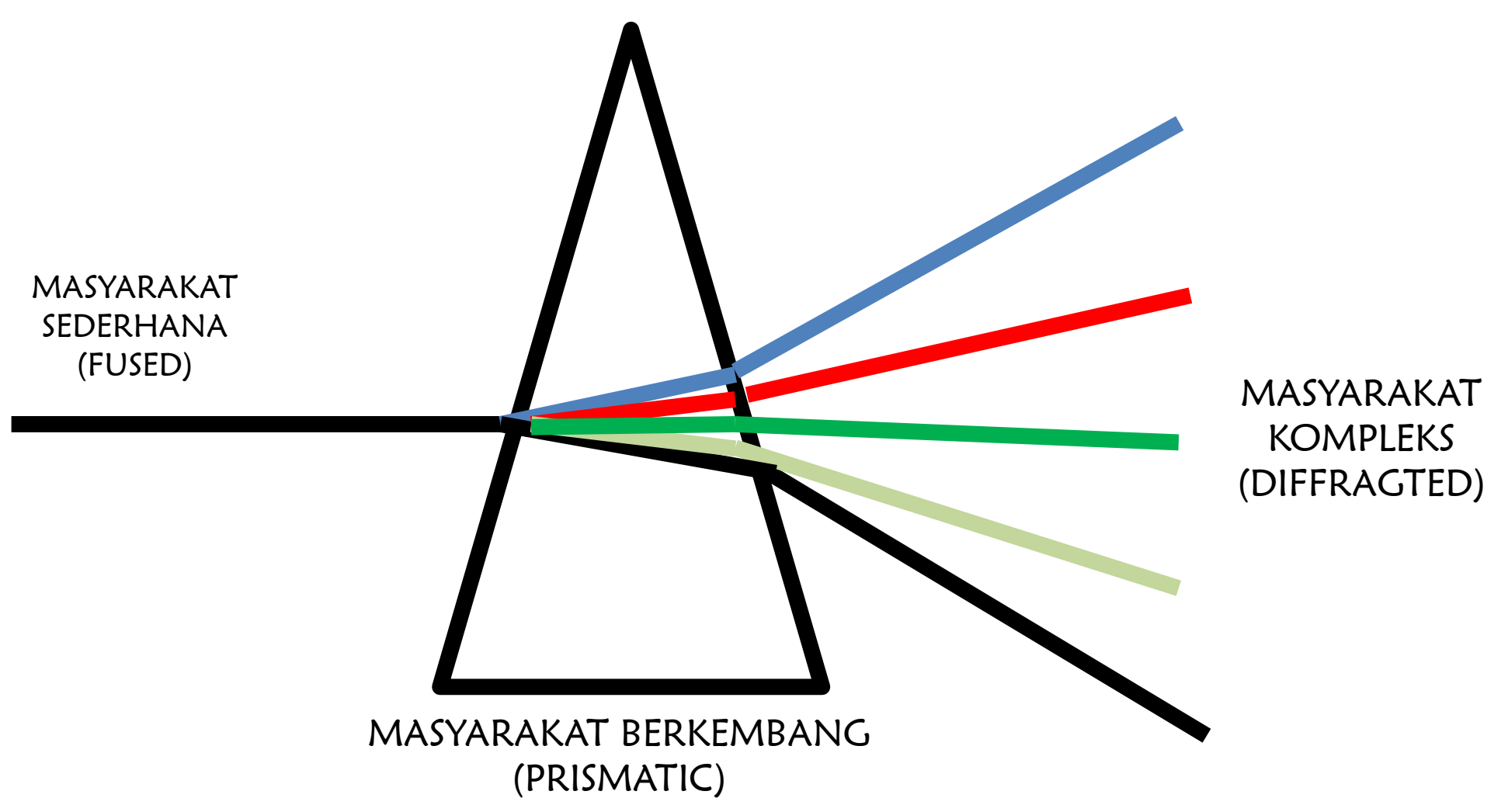

(2) Sehebat mana menghadapi sekulrasisasi dan modernisasi akan menentukan arah pembentukan peran dan fungsi masjid bagi umat Islam

LIMA TAHAP PERKEMBANGAN MASYARAKAT MENURUT WN ROSTOW

TRADISIONAL SOCIETY
THE PRECONDITION OF THE TAKE OFF
THE TAKE OFF
THE DRIVE
TO MATURITY

THE AGE OF HIGH MASS

CONSUMPTION 

BERBAGAI DAERAH INDONESIA (BERDASARKAN KAJIAN KASUS DI MEDAN)

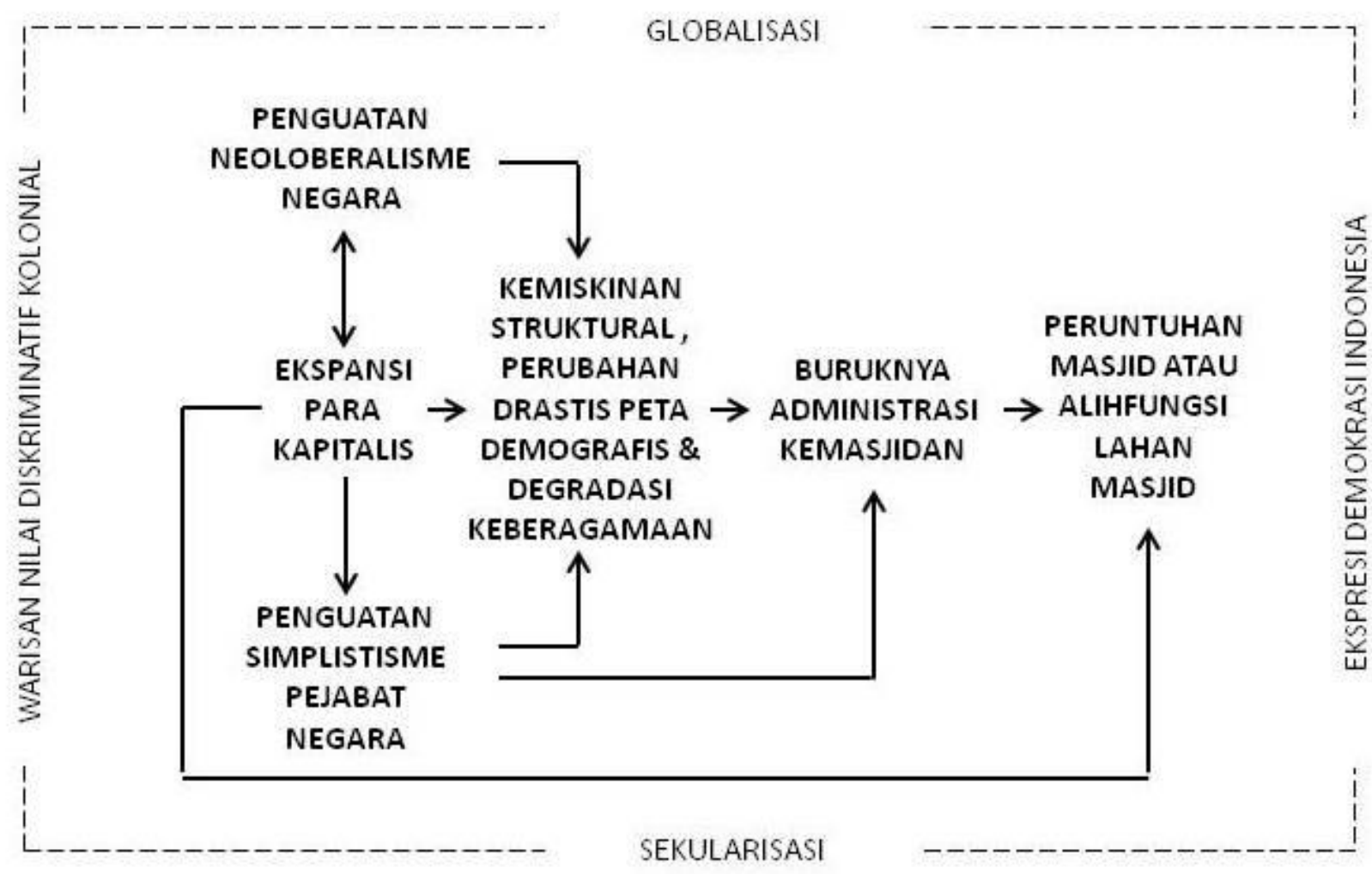




\section{REVITALISASI:}

SARAN

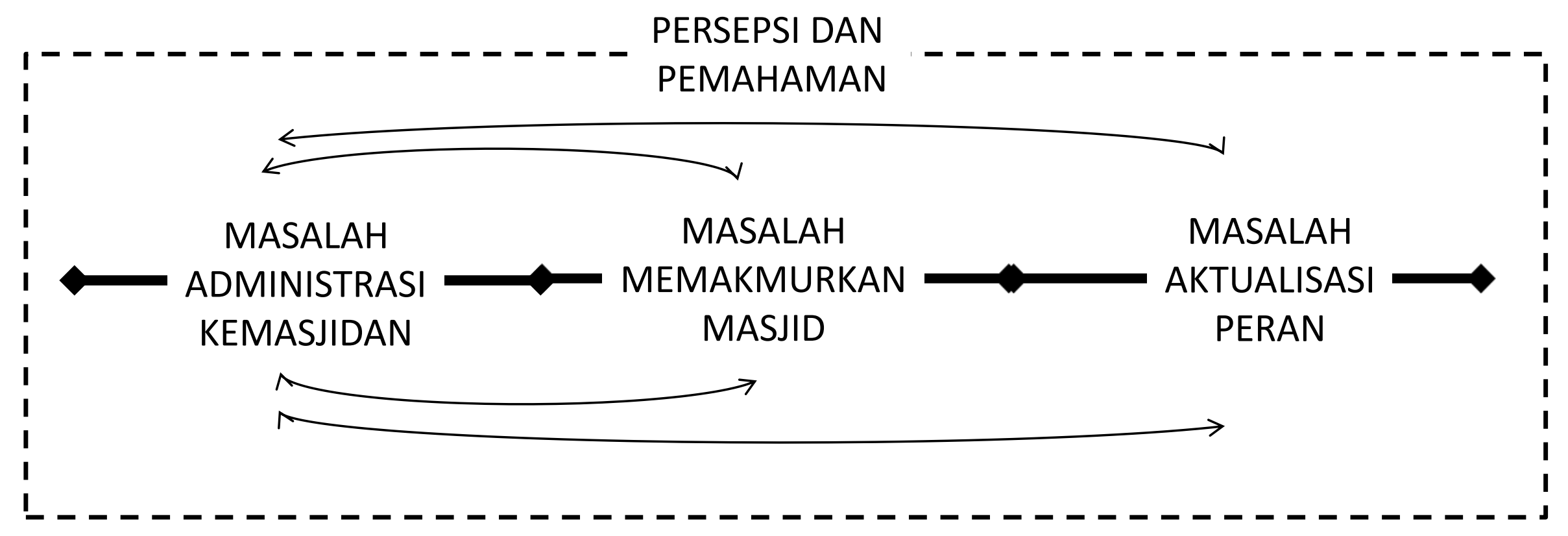

Persepsi dan pemahaman masyarakat terhadap masjid akan mewarnai model pengelolaan masjid dilihat dari pemberian peran dan fungsinya di tengah masyarakat. Administrasi kemasjidan akan ditentukan dan sekaligu menentukan masalah-masalah lainnya seperti kemakmuran masjid dan aktualisasi masjid. Bagi orang yang berfikir amat sederahana, masjid hanyalah tempat sholat dan zikir lima waktu. Sedangkan bagi yang lain masjid harus menjadi pusat badah dan pusat kebudayaan Islam. 